SR 193

CRREL

Special Report 193

\title{
ANALYSIS OF VAPORS \\ EMITTED FROM MILITARY MINES
}

T.F. Jenkins, W.F. O'Reilly, R.P. Murrmann,

D.C. Leggett and C.I. Collins

September 1973

\author{
U.S. ARMY MOBILITY EQUIPMENT RESEARCH AND DEVELOPMENT CENTER \\ DA PROJECT 1G672712AJ22 \\ BY \\ CORPS OF ENGINEERS, U.S. ARMY \\ COLD REGIONS RESEARCH AND ENGINEERING LABORATORY
}

HANOVER, NEW HAMPSHIRE 
The findings in this report are not to be construed as an official Department of the Army position unless so designated by other authorized documents. 


\title{
ANALYSIS OF VAPORS EMITTED FROM MILITARY MINES
}

\author{
T.F. Jenkins, W.F. O'Reilly, R.P. Murrmann, \\ D.C. Leggett and C.I. Collins
}

September 1973

\author{
PREPARED FOR \\ U.S. ARMY MOBILITY EQUIPMENT RESEARCH AND DEVELOPMENT CENTER \\ DA PROJECT 1G672712AJ22 \\ BY \\ CORPS OF ENGINEERS, U.S. ARMY \\ COLD REGIONS RESEARCH AND ENGINEERING LABORATORY \\ HANOVER, NEW HAMPSHIRE
}




\section{PREF ACE}

This report was prepared by T.F. Jenkins, Research Chemist, First Lieutenant W.F. O'Reilly, Chemist, and D.C. Leggett, Chemist, under the supervision of Dr. R.P. Murrmann, Earth Sciences Branch, Research Division, U.S. Army Cold Regions Research and Engineering Laboratory (USA CRREL) in association with C.I. Collins, Research Chemist, of the Mine Detection Division, U.S. Army Mobility Equipment Research and Development Center (USA MERDC). The work was supported by USA MERDC under DA Project 1G672712AJ22. The report was technically reviewed by James Cragin, USA CRREL, and R.A. Konyneburg, USA MERDC.

The contents of this report are not to be used for advertising, publication, or promotional purposes. Citation of trade names does not constitute an official endorsement or approval of the use of such commercial products.

Manuscript received 10 May 1973. 


\section{CONTENTS}

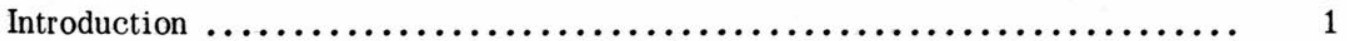

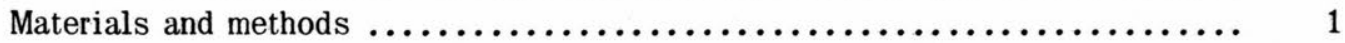

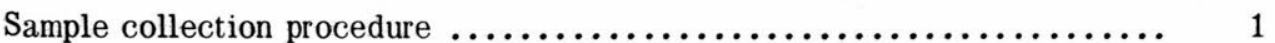

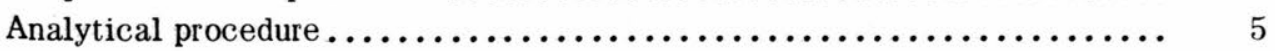

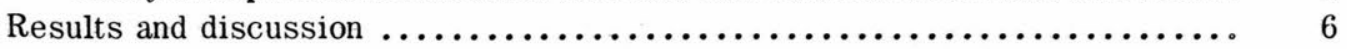

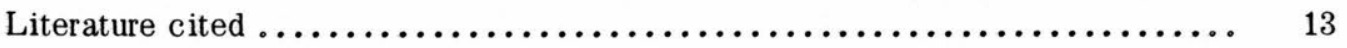

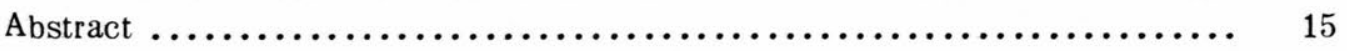

\section{ILLUSTRATIONS}

Figure

1. M15 metallic antitank mine prepared for sample collection ........... 2

2. M19 nonmetallic antitank mine prepared for sample collection ......... 2

3. M14 nonmetallic antipersonnel mine prepared for sample collection...... 3

4. M16 metallic antipersonnel mine prepared for sample collection ....... 3

5. Chromosorb 102 collection tube used to concentrate vapors from mines .. 5

6. Modification of gas chromatograph injection port for use with collection tube 6

7. Block diagram of $\mathrm{GC} / \mathrm{MS}$ analytical system $\ldots \ldots \ldots \ldots \ldots \ldots \ldots \ldots . \ldots 6$

8. Chromatograms of zero air taken with and without pretrapping $\ldots \ldots \ldots \ldots .7$

9. Chromatogram of empty bag sample $\ldots \ldots \ldots \ldots \ldots \ldots \ldots \ldots \ldots \ldots \ldots . .6$

10. Chromatograms of samples taken from bags containing M19 and M15 anti-

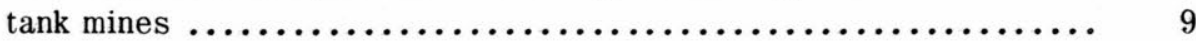

11. Chromatograms of samples taken from bags containing M14 and M16 antipersonnel mines.................................... 10

12. Chromatograms of samples taken from bags containing M19 and M15 (inert)

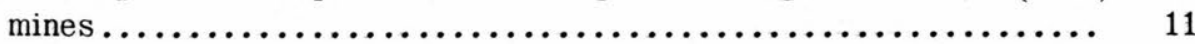

13. Chromatogram obtained for sample from bag containing M16 (inert) mine.. 12

14. Chromatogram obtained for sample from bag containing M14 (inert) mine.. 12

\section{TABLES}

Table

I. Description of mines ................................. 4

II. Compounds identified with the mass spectrometer for the chromatograms shown in Figures 8-14 


\title{
ANALYSIS OF VAPORS EMITTED FROM MILITARY MINES
}

\author{
by \\ T.F. Jenkins, W.F. O’Reilly, R.P. Murrmann, \\ D.C. Leggett and C.I. Collins
}

\section{INTRODUCTION}

The concept of using trace gas detection to locate military explosives and emplaced mines has been under investigation for several years. ${ }^{1} 23689101112$ The usefulness of this approach depends on the ability to detect signature vapors close to their source. Many investigations in the past have sought detailed characterization of the composition of solid explosive materials. Although this information is potentially useful, it is not practical to predict the composition of the vapor arising from the solid strictly from this type of data alone. Volatile impurities which are present at low levels in the solid explosive may contribute significantly to the composition of the vapor. Since it is the vapor which is potentially useful for detection, information concerning the composition of this effluent is important.

In an earlier study, ${ }^{12}$ cyclohexanone was identified as a major constituent of the vapor evolved from the solid military explosive composition B. Cyclohexanone is not a component of the explosive itself but is rather a solvent used in the recrystallization of cyclonite (cyclotrimethylene-trinitramine), a major component of composition B. ${ }^{5}$ The purpose of this study was to determine whether cyclohexanone, as well as other components of the explosive and mine hardware, could be detected in the vapor evolving from intact mines filled with military explosives.

\section{MATERIALS AND METHODS}

\section{Sample collection procedure}

Four representative types of military mines were selected for study. This group included metallic and nonmetallic antitank and antipersonnel mines. The chosen group also represented a variety of military explosives including composition B, tetryl, and TNT. Three mines of each type, without fuses, were placed individually in $27 \times 27$-in. $(68.6 \times 68.6-\mathrm{cm})$ polyethylene glove bags (Table I). The opening to each bag was folded and sealed with tape. A $1 / 4^{-i n}$. $(0.63-\mathrm{cm})$ Swagelok connector was provided for sample removal. The bags were flushed for about ten minutes and then inflated with 30 liters of zero grade air.* For reference purposes, two empty bags (no mines) and bags containing one inert mine of each type were also prepared. The plastic bags were stored at room temperature in covered Nalgene containers (Fig. 1-4) in an explosive storage magazine at MERDC.

\footnotetext{
* Zero grade air contains less than $2 \mathrm{ppm}$ of total hydrocarbon impurities.
} 


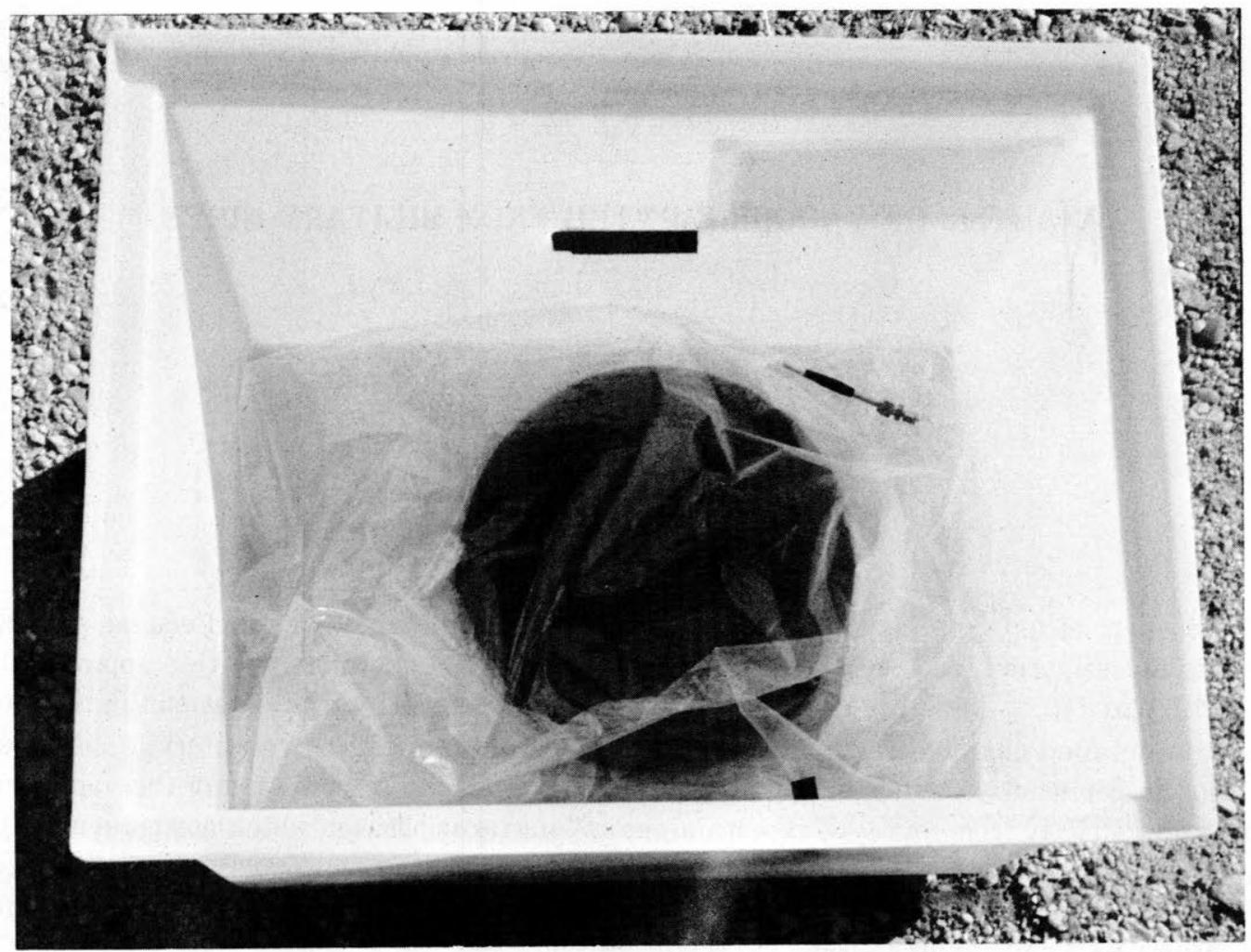

Figure 1. M15 metallic antitank mine prepared for sample collection.

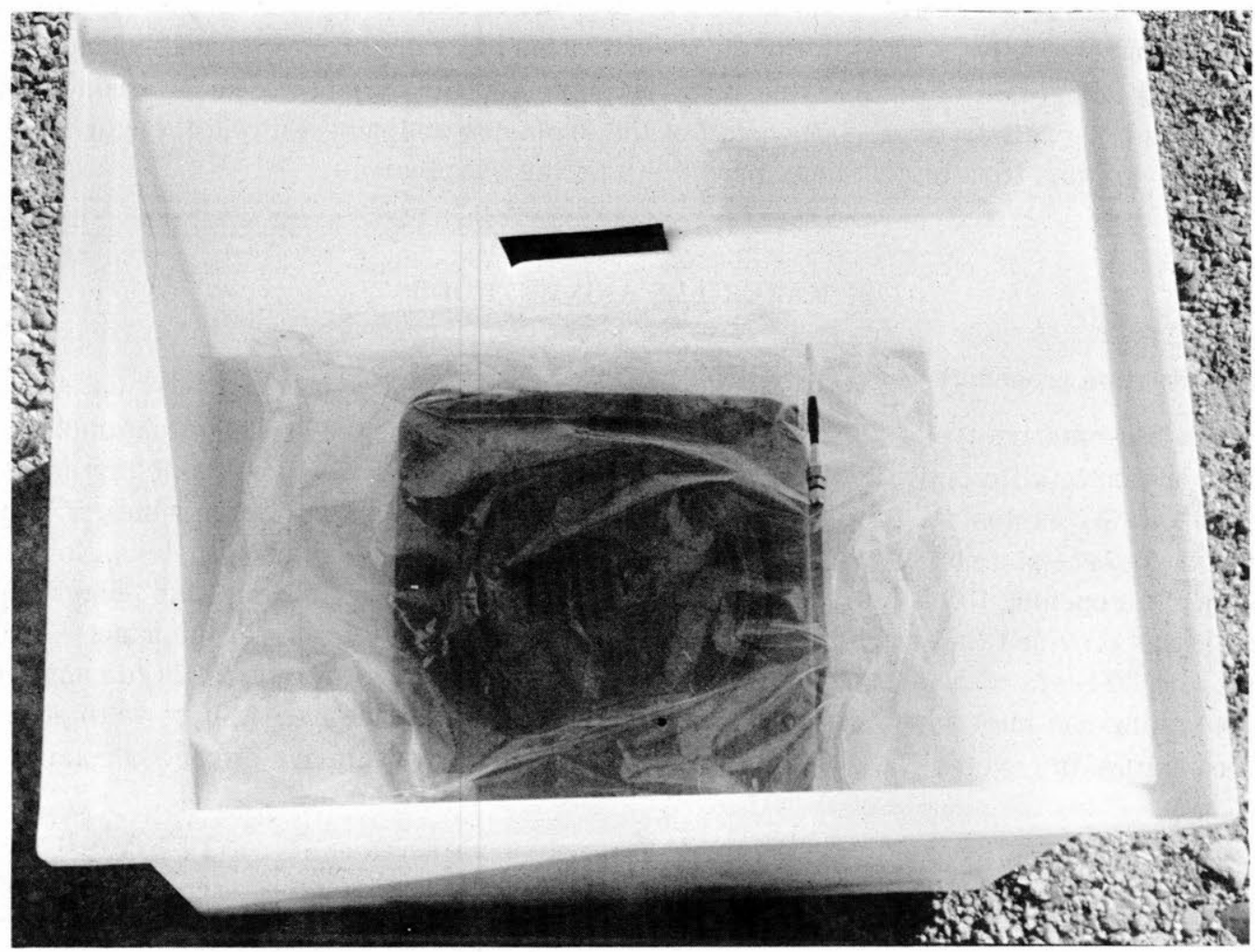

Figure 2. M19 nonmetallic antitank mine prepared for sample collection. 


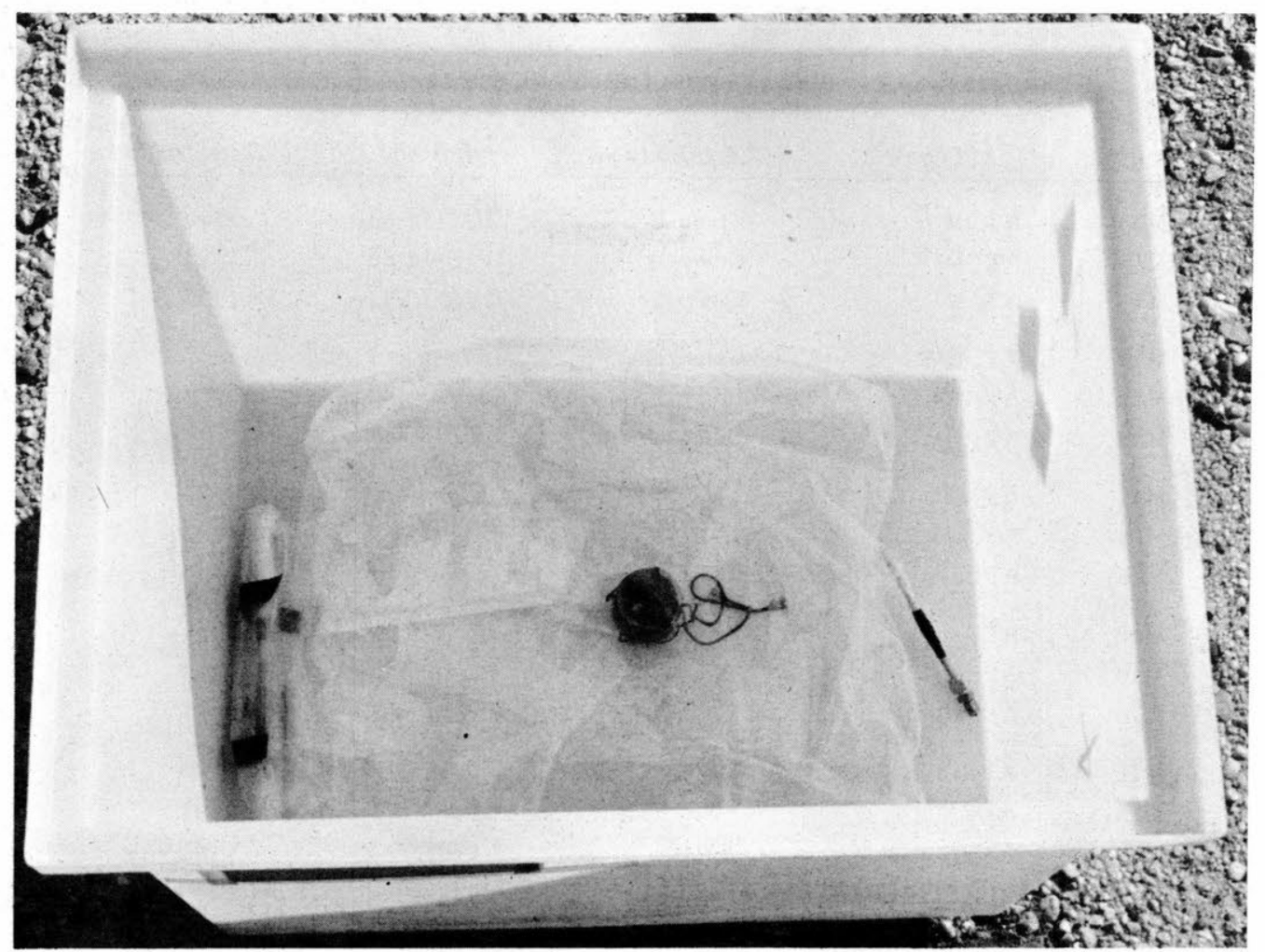

Figure 3. M14 nonmetallic antipersonnel mine prepared for sample collection.

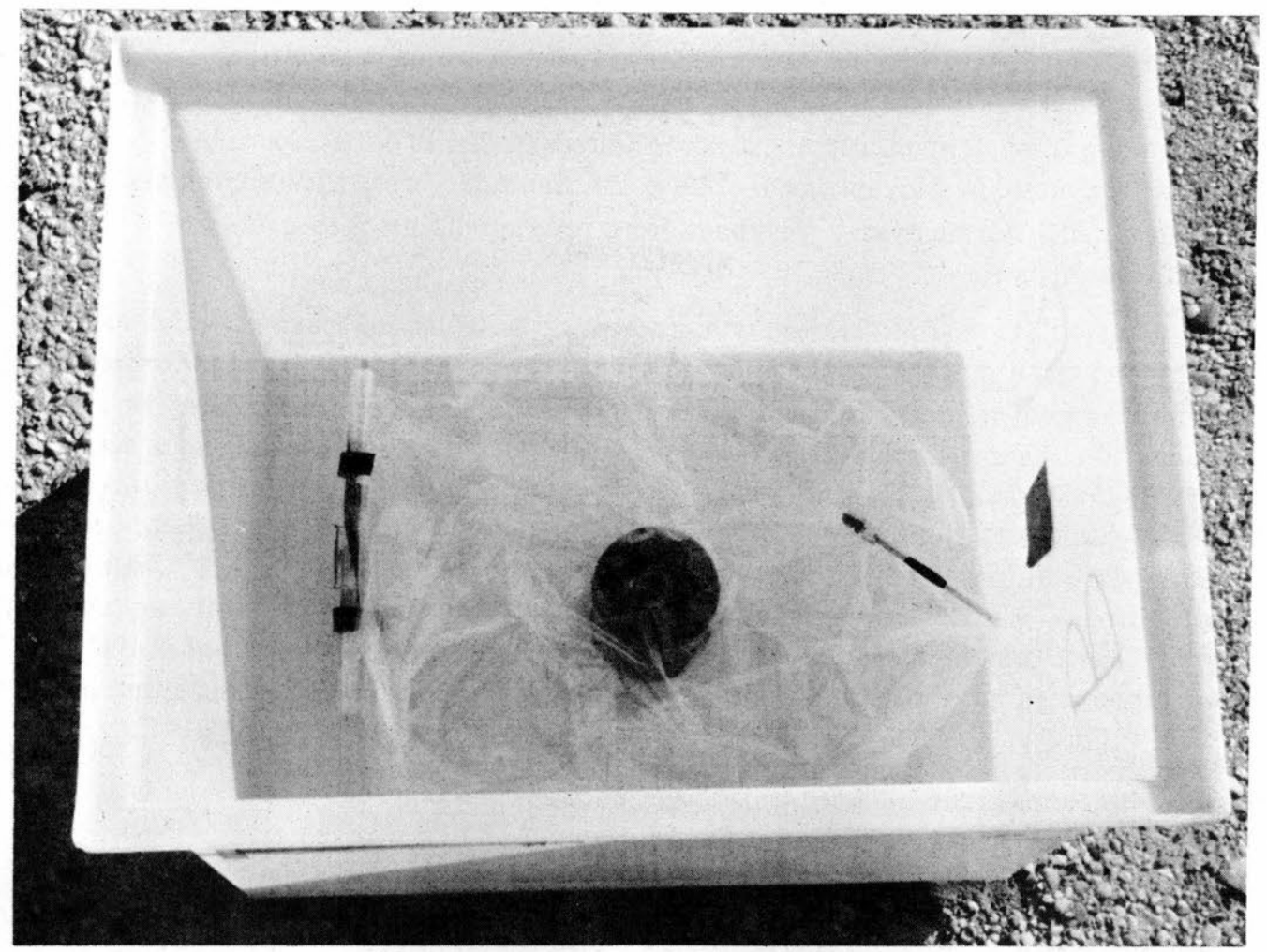

Figure 4. M16 metallic antipersonnel mine prepared for sample collection. 
Table I. Description of mines.

\begin{tabular}{rllll} 
Mine & \multicolumn{1}{c}{ Type* } & Explosive & \multicolumn{1}{c}{ Lot no. } & Date loaded \\
\hline M15 & A T, M & Comp B & LOP-14-14 & 1953 \\
M15 & AT, M & Comp B & LOP-14-80 & 1953 \\
M15 & AT, M & Comp B & RVA 16-1 & 1953 \\
M19 & AT, NM & Comp B & LOD-500-1 & 1967 \\
M19 & AT, NM & Comp B & LOD-500-1 & 1967 \\
M19 & AT, NM & Comp B & LOD-500-1 & 1967 \\
M14 & AP, NM & Tetryl (102) & LOP-15-56 & 1953 \\
M14 & AP, NM & Tetryl (102) & LOP-15-56 & 1953 \\
M14 & AP, NM & Tetryl (102) & LOP-15-56 & 1953 \\
M16 & AP, M & TNT & PA 27-4 & 1954 \\
M16 & AP, M & TNT & PA 27-4 & 1954 \\
M16 & AP, M & TNT & PA 27-4 & 1954 \\
M19 & AT (inert), NM & None & PASR-20-57 & 1958 \\
M14 & AP (inert), NM & None & 3A-2-64 & 1964 \\
M15 & AT (inert), M & None & Unknown & Unknown \\
M16 & AP (inert), M & None & Unknown & Unknown \\
\hline * M metallic & & & \\
NM $=$ nonmetallic & & & \\
AP $=$ antipersonnel & & & \\
A T $=$ antitank & & &
\end{tabular}

One month later, a complete set of preliminary samples was collected by drawing 30 liters of air from each bag through specially constructed Chromosorb 102 collection tubes ${ }^{4}$ (Fig. 5) at 2 liters/min with a portable vacuum pump. The collection tubes were then sealed and returned to the laboratory at CRREL for analysis. The bags were reinflated with zero grade air to allow further sampling at a later date.

The collection tubes (Fig. 5) were constructed in the following manner. Four inches $(10.2 \mathrm{~cm})$ of $3 / 4$-in. (1.9-cm) OD stainless steel tubing was packed with $5 \mathrm{~g}$ of $60-80$ mesh Chromosorb 102 . The packing was held in place by two 100-120 mesh stainless steel screens, one of which was spring loaded to reduce the possibility of channeling. The ends of the tubes were reduced to $1 / 8$-in. $(3.2 \mathrm{~mm})$ OD by end caps which had been heliarc welded in place. The $1 / 8$-in. OD tubing was equipped with Swagelok tube fittings at both ends, providing a seal to prevent contamination. The collection tubes were prepared prior to sampling by baking for four days at $200^{\circ} \mathrm{C}$ while purging with zero grade nitrogen at a flow of $50 \mathrm{ml} / \mathrm{min}$. The bakeout was then continued for an additional two days at $100^{\circ} \mathrm{C}$ with a molecular sieve trap cooled with liquid nitrogen installed in the purge gas line. The tubes were capped with Swagelok plugs except during periods of sampling and analysis.

The results from the preliminary analyses indicated possible contamination of the samples with impurities in the zero grade air used to inflate the bags. To correct for this, the bags were evacuated, flushed and refilled with 30 liters of zero grade air which was purified using a $1 / 2$-in. Chromosorb 104 trap cooled with dry ice. After another four-month period, a final complete set of samples was collected for analysis by exhausting the air from the bags through Chromosorb 102 collection tubes at a rate of 2 liters/min. 


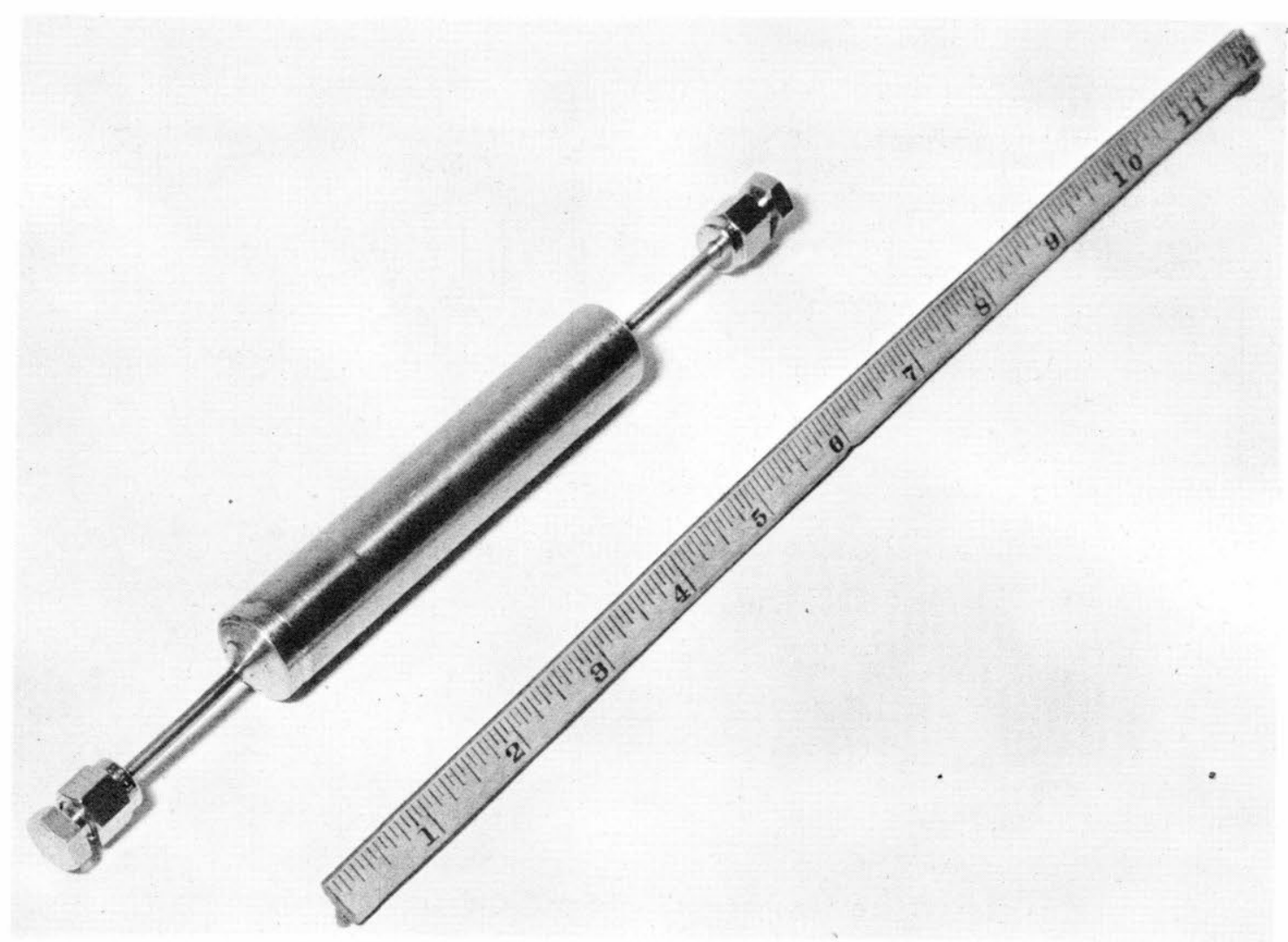

Figure 5. Chromosorb 102 collection tube used to concentrate vapors from mines.

\section{Analytical procedure}

In the laboratory the sample collection tubes were attached to the injection port of either a Perkin-Elmer 270 gas chromatograph/mass spectrometer (GC/MS) or to a Perkin-Elmer 900 gas chromatograph (GC). The injection ports of both instruments were modified as shown in Figure 6 to allow for direct transfer of the samples from the collection tubes. A block diagram of the GC/MS analytical system is shown in Figure 7. Regardless of the analytical instrument used, the tubes were first flushed in the direction of sample collection with zero grade helium ${ }^{7}(50 \mathrm{ml} / \mathrm{min}$ for 30 minutes at $23^{\circ} \mathrm{C}$ ) which removes air, carbon dioxide, water, and most of the low molecular weight hydrocarbons up to n-butane (Fig. 6a). The unattached end of the collection tube was then connected with Teflon tubing to a two-way valve on the helium supply. With the valve configured for helium flow to bypass the collection tube direct to the GC column, the GC column was preconditioned at $150^{\circ} \mathrm{C}$ for 15 minutes. The GC oven was then cooled to $-75^{\circ} \mathrm{C}$, and the two-way valve positioned to cause helium to flow $(50 \mathrm{ml} / \mathrm{min}$ ) through the collector tube before entering the GC column (Fig. 6b). The collection tube was subsequently heated to $120^{\circ} \mathrm{C}$ for one hour during which time trapped components were backflushed from the collection tube and concentrated on the head of the GC column. (Previous studies have indicated a transfer efficiency of greater than $80 \%$ under these conditions for compounds up to and including cyclohexanone.) After the 1-hour transfer period, the two-way valve was repositioned so that helium again flowed directly through the GC column (Fig. 6c). The flow rate was reduced to $25 \mathrm{ml} / \mathrm{min}$. The analytical procedure depended on the type of GC column used, either a 9-ft (2.75-m) Durapak column (Carbowax 400 chemically bonded to Porasil C) or a 3-ft (0.92-m) DC-200 column (15\% DC-200 on Anakrom ABS). For the sample 


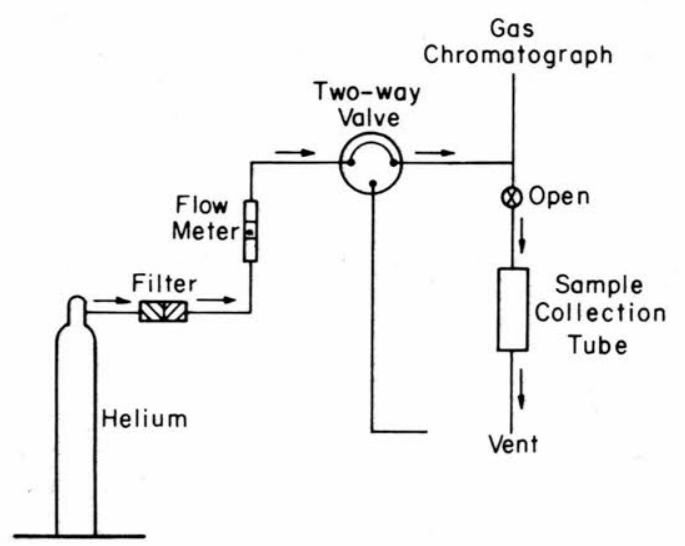

a. Flushing sample

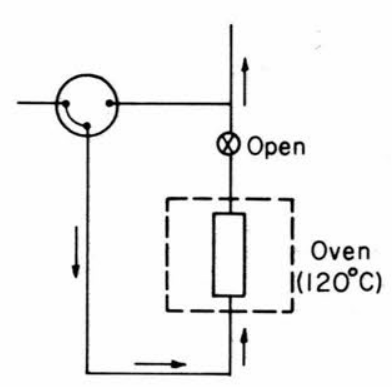

b. Sample elution

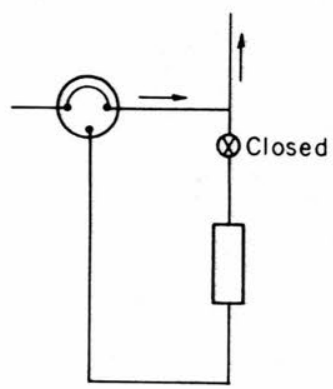

c. Sample analysis

Figure 6. Modification of gas chromatograph injection port for use with collection tube.

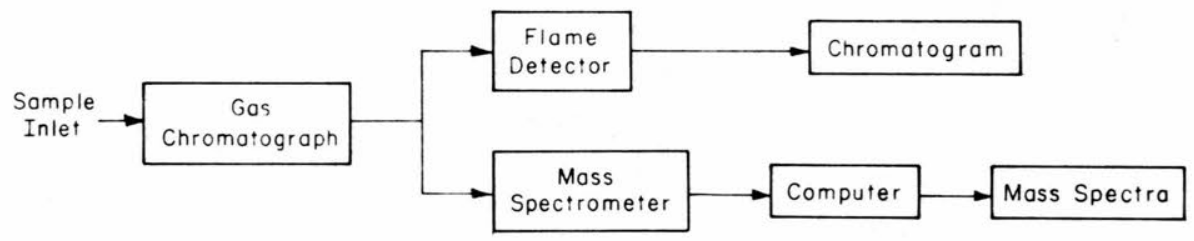

Figure 7. Block diagram of GC/MS analytical system.

analyses on Durapak, the GC oven was programmed from $-75^{\circ} \mathrm{C}$ to $150^{\circ} \mathrm{C}$ at $16^{\circ} / \mathrm{min}$. Using the DC-200 column, the temperature was programmed from $-75^{\circ} \mathrm{C}$ to $200^{\circ} \mathrm{C}$ at $20^{\circ} / \mathrm{min}$. Effluent from the column on the GC/MS was split $70 \%$ to the mass spectrometer and $30 \%$ to a flame ionization detector. The flame ionization detector was used to quantify effluent peaks and to indicate the correct time for scans to be taken with the mass spectrometer. The mass spectra obtained were used in conjunction with GC retention times as a means of identifying those peaks appearing on the flame ionization chromatogram. A PDP-12 laboratory computer was used for on-line acquisition, processing and storage of mass spectral data.

The few samples run on the Perkin-Elmer 900 gas chromatograph were analyzed using an electron capture detector.

\section{RESULTS AND DISCUSSION}

During the preliminary chromatographic analyses, even the samples obtained from the empty polyethylene bags showed several large peaks. Thus, it appeared that the zero grade air used initially to fill the bags contained too high a level of organic contaminants to be used directly for this type of work. To examine this possibility, a 30-liter sample was taken directly from the zero grade air cylinder using one of the collection tubes. The chromatogram of this sample (Fig. $8 \mathrm{~b}$ ) was obtained using a flame ionization detector. The numbers associated with the various peaks refer to the compounds listed in Table II, which were identified from mass spectra. The results from this sample showed that zero grade air would require further purification. In order to alleviate this problem, the bags were evacuated, flushed, and refilled with zero grade air that had been 


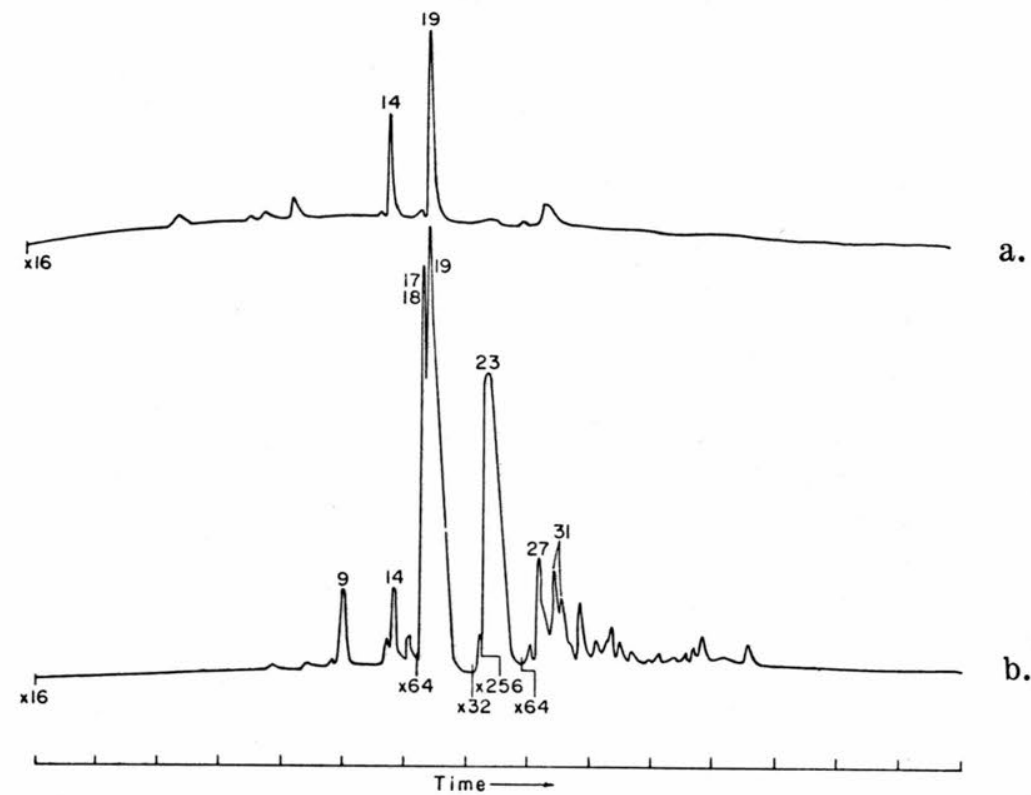

Figure 8. Chromatograms of zero air taken with (a) and without (b) pretrapping. Numbers refer to compounds listed in Table II.

Table II. Compounds identified with the mass spectrometer for the chromatograms shown in Figures 8-14.
1. $\cos$
19. Trichloroethylene
2. Propane<smiles>CCCCCCCCCCCC</smiles>
20. Acetone
3. Propene
21. Butanal
4. Is obutane

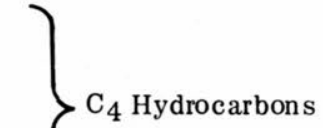
22. Heptane
5. N-Butane
23. Toluene
6. Butene
24. Me thyle thylke tone
7. Butadiene
25. E thylbenzene
8. Isopentane
26. Me thyli sopropylketone
9. N-Pentane

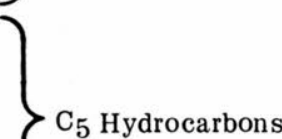
10. Pentene \} $\mathrm{C}_{5}$ Hydrocarbons
27. Xylene
28. Styrene
11. Pentadiene
29. Hexanone
12. Acetaldehyde
30. $\mathrm{C}_{3}$ Aromatic
13. Isohexane
14. N-Hexane

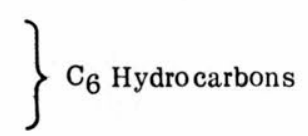
31. $\mathrm{C}_{10-14}$ Hydrocarbon
15. Hexene
32. Unknown $(207+$ peak $)$
16. Propanal
33. Benzaldehyde
17. Benzene
34. Ethylstyrene
18. Methylchloride
35. Cyclohexanone
36. Water 


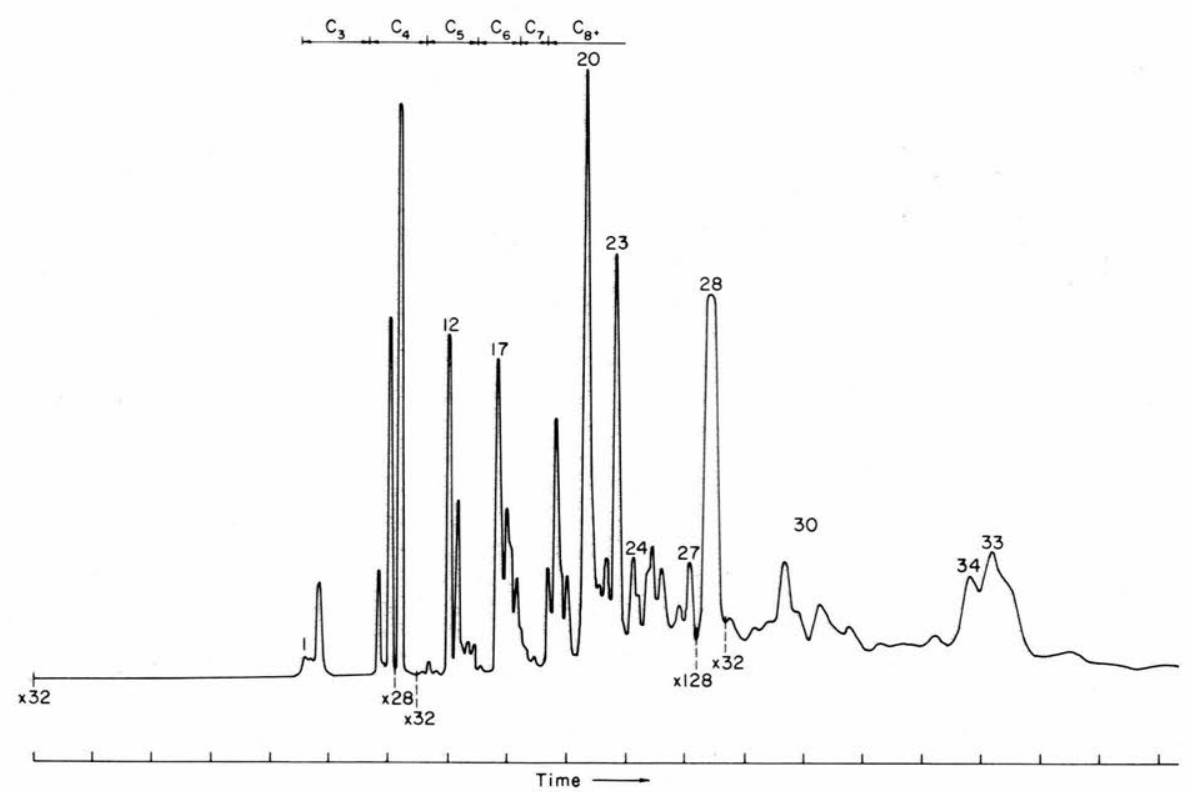

Figure 9. Chromatogram of empty bag sample.

previously trapped with a Chromosorb 104 trap maintained at dry ice temperature. Figure 8a shows a chromatogram obtained for a 30-liter sample of trapped zero grade air following this procedure. Clearly, the level of background contamination was considerably reduced.

Even with this significant improvement in procedure, the chromatograms obtained for the final sampling period were difficult to interpret. Figures 9-14 are representative chromatograms obtained using the flame ionization detector on the GC/MS for the various classes of samples. It is evident that all of the samples including the empty bag (Fig. 9) contained a large number of compounds. Significant concentrations of $\mathrm{C}_{4}, \mathrm{C}_{5}$, higher molecular weight hydrocarbons, several aromatics including benzene, toluene, xylene, styrene, and ethylstyrene, several oxygenated compounds such as acetaldehyde, acetone, methylethylketone, and benzaldehyde, and several halogenated compounds such as trichloroethylene show up as a relatively constant background in all types of samples. Some of these compounds could have resulted from incomplete removal of adsorbed contaminants present in the zero grade air used to fill the bags. Other compounds may have originated from the polyethylene bags themselves. Several of these compounds including acetaldehyde, xylene, styrene, ethylstyrene, and benzaldehyde have been found to be decomposition products of the Chromosorb 102 used in the construction of the air sampling tubes. Even with this substantial number of background chemicals, individual differences among the various types of samples from intact mines and mine casings were observed. The differences discussed below are those that have been found to be consistent among replicates of a given class of mines as well as for both the preliminary and final sets of samples.

The most significant result of this study was the detection of cyclohexanone in the bags containing the M15 (metallic) and M19 (nonmetallic) antitank mines. These were the only types of mines studied that were charged with composition B. In an earlier investigation ${ }^{12}$ cyclohexanone was shown to be a significant constituent in the vapor evolving from composition B. Cyclohexanone was not detected in the vapor from any other type of mine nor in the vapor from inert mine casings or in the empty bags. Thus, vapors from the explosives are detectable outside of intact mines. Cyclohexanone was found in consistently higher concentrations in the bags containing the M15 (metallic) 


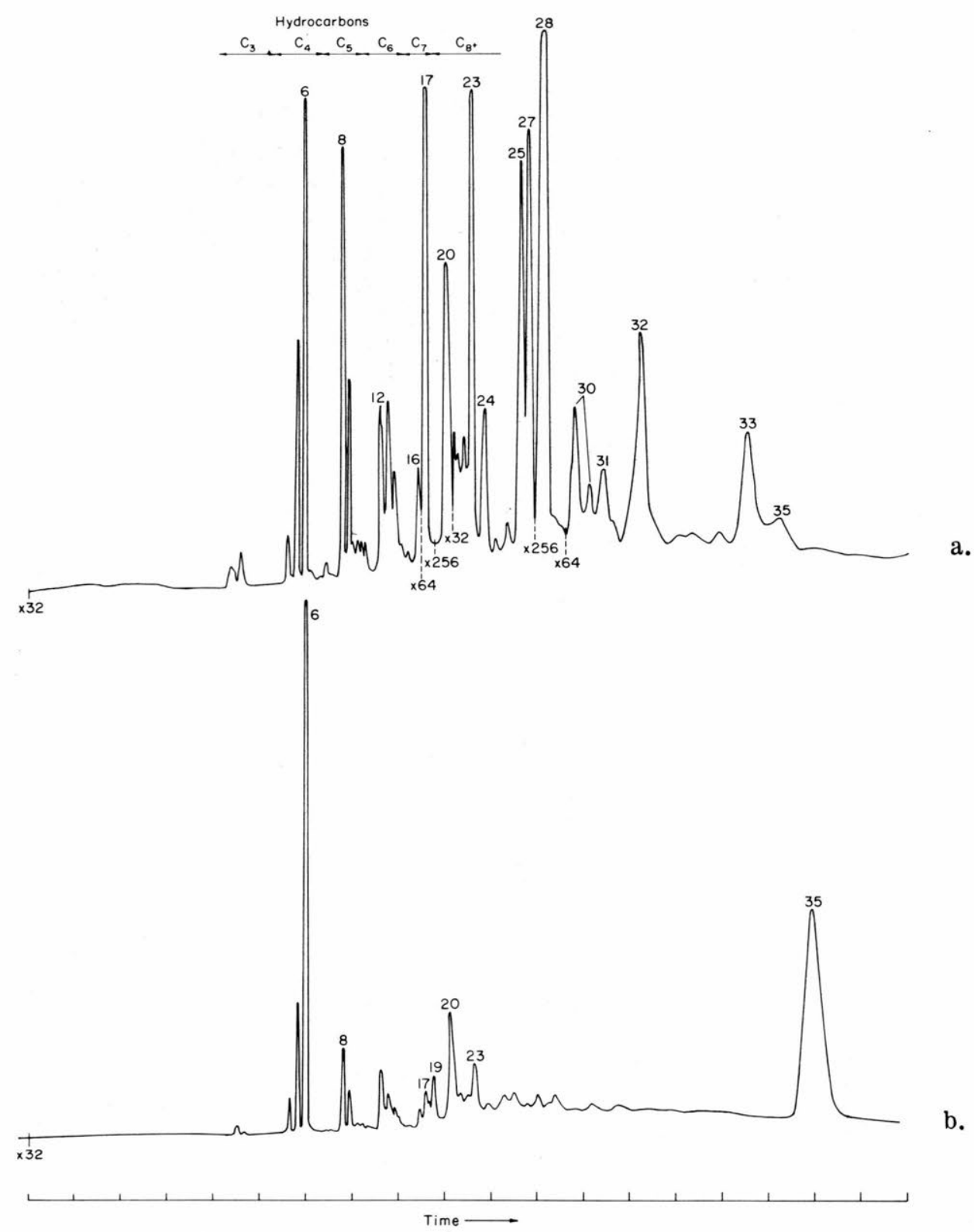

Figure 10. Chromatograms of samples taken from bags containing M19 (a) and M15 (b) antitank mines.

mines than in those containing the M19 (nonmetallic) mines. The concentrations found were about $80 \mathrm{ppb}$ (by volume) in the bags containing the M15 mines and $5 \mathrm{ppb}$ in those containing the M19 mines. Examples of the chromatograms obtained for vapors from these mines are shown in Figure 10. Peak 35 in all cases represents the response of the detector to the cyclohexanone found in the sample.

Although acetone was found in all of the samples, substantially larger amounts were consistently observed in the bags containing the M19 mines and M19 casings (Fig. 10, 12). Acetone is, therefore, probably evolving from the materials used in construction of M19 nonmetallic casings. 


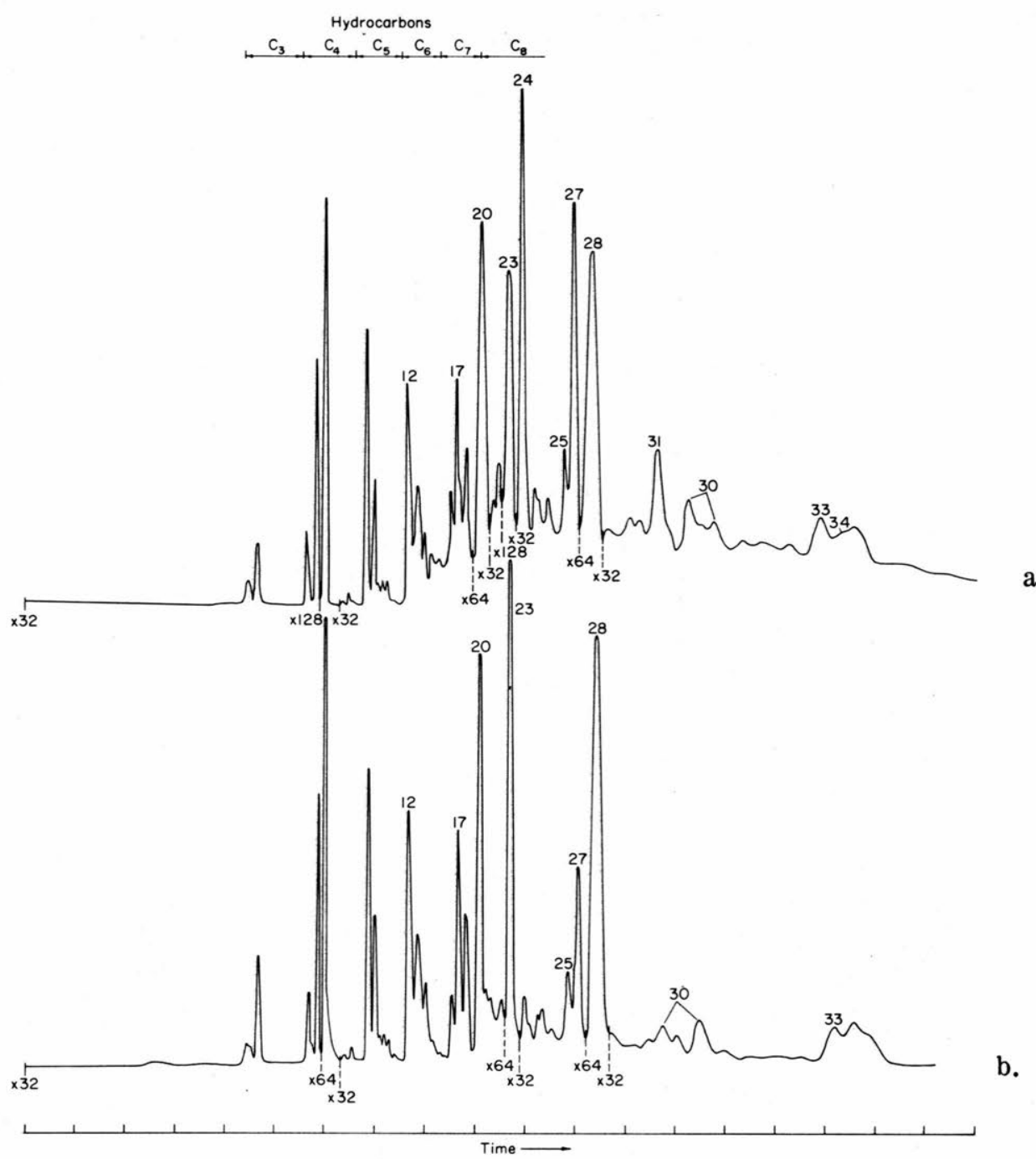

a.

Figure 11. Chromatograms of samples taken from bags containing M14 (a) and M16 (b) antipersonnel mines.

Toluene, although also present in the background, was found at larger concentrations in the M19, M19 casing, M14, and M16 samples (Fig. 10-12). The origin of this compound is unknown.

Relatively large concentrations of one unidentified compound appeared in the samples from the bags containing the M19 and M19 casings. We were unable to identify this component although it gave a large mass spectral peak at $\mathrm{m} / \mathrm{e}=207$. Several larger molecular weight ions also seemed to be associated with this compound although its exact mass spectrum could not be determined due to interferences from other sample components. This species appears to be a silicon-containing compound which is associated with the nonmetallic casing used in the construction of the M19 mine.

Several samples were analyzed using an electron capture detector. Because of the limited number of samples available, only those from M14 and M16 mines were included. Due to the extreme sensitivity of this detector to electronegative compounds, the resultant chromatograms contained a large number of peaks, most of which were not identified. In the case of samples from the 


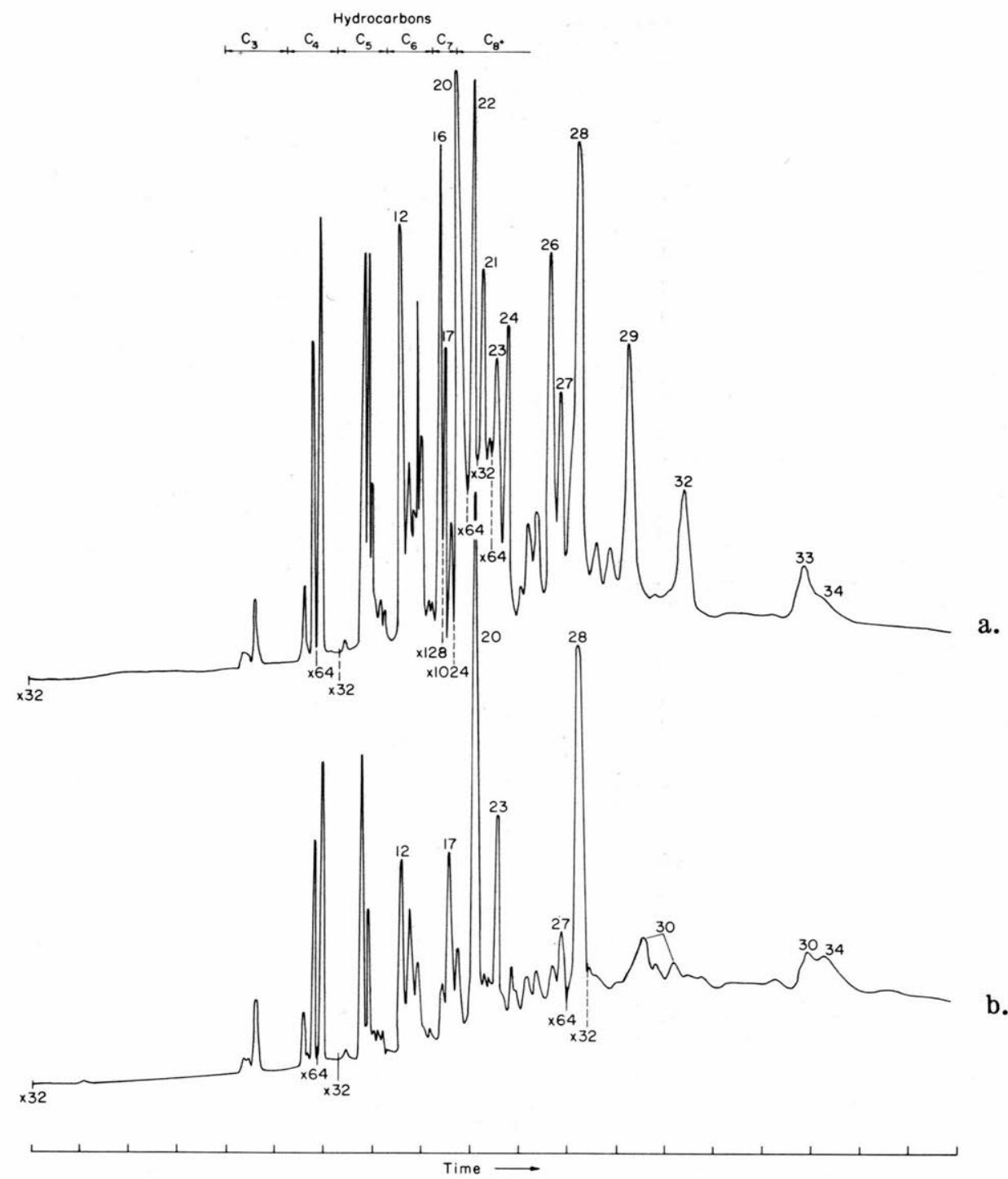

Figure 12. Chromatograms of samples taken from bags containing M19 (a) and M15 (b) (inert) mines.

M16 mine, however, a peak was observed at a retention time exactly corresponding to that of 2,4 , 6 trinitrotoluene. Although this peak was easily detectable using the electron capture detector, which has a detection limit of about $10^{-12} \mathrm{~g}$ for $2,4,6 \mathrm{TNT}$, the level was far below that needed for positive mass spectral identification. This compound did not appear in the sample from the empty bag or in the M14 sample; therefore, it is believed to be associated with the M16 mine. Since the explosive used in the M16 is TNT, it is expected that this compound would be present in the emitted vapor. Although positive identification is clearly lacking, it is our feeling that this peak indeed is $2,4,6$ trinitrotoluene. It is unfortunate that additional samples from the two types of mines containing composition B were not collected for analysis with the electron capture detector. One of the major components of composition B is TNT and, hence, there is also a possibility of detecting TNT in the vapors from these mines. 


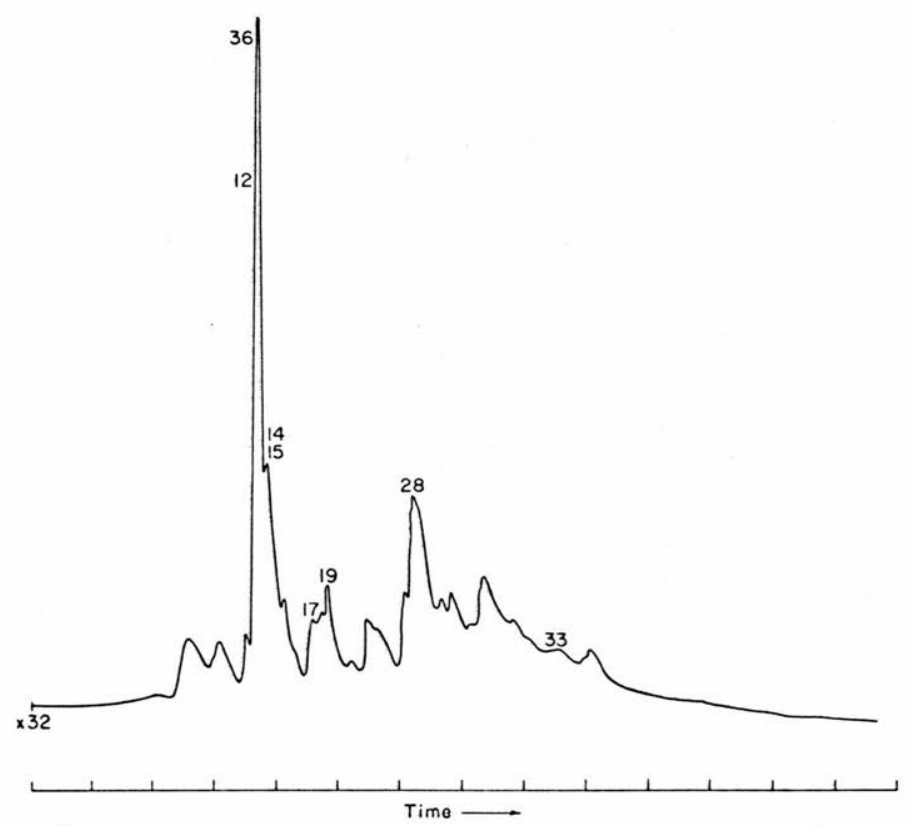

Figure 13. Chromatogram obtained for sample from bag containing M16 (inert) mine.

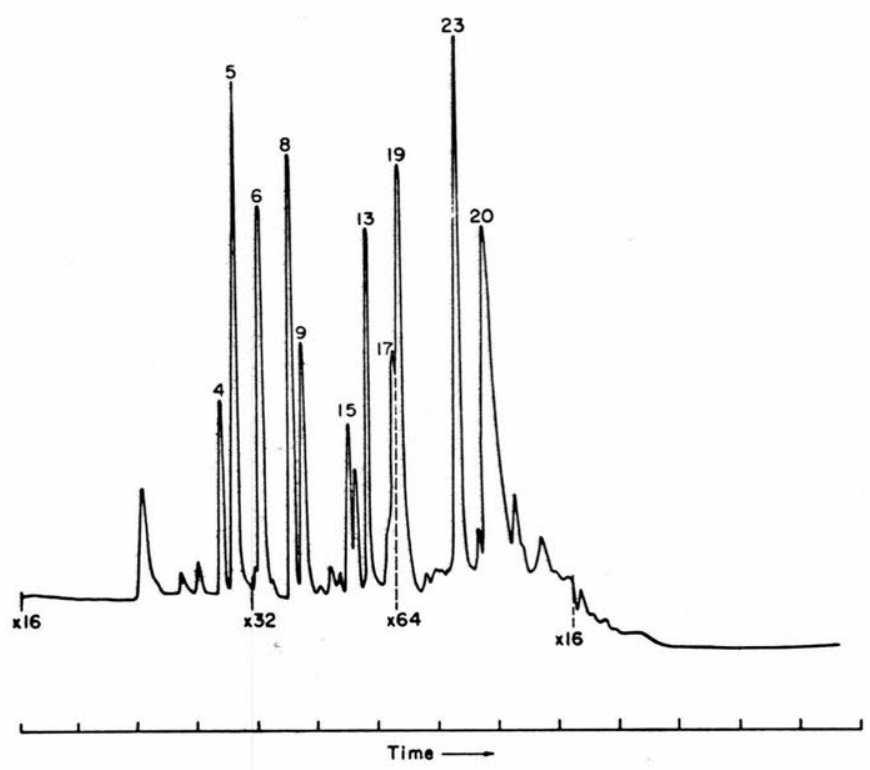

Figure 14. Chromatogram obtained for sample from bag containing $M 14$ (inert) mine. 


\section{LITERATURE CITED}

1.

2.

3.

4.

5.

6. Jenkins, T.F., R.P. Murrmann and D.C. Leggett (In press) Mass spectra of the isomers of trinitrotoluene. Journal of Chemical and Engineering Data.

7. Leggett, D.C., R.P. Murrmann, T.F. Jenkins and R. Barriera (1972) A method for concentrating and determining trace organic compounds in the atmosphere. USA CRREL Special Report 176. AD 745125.

8. McKee, H.C. and H.P. Burchfield (1961) Task report on clathrate sniffer evaluation. U.S. Army Engineer Research and Development Laboratory, Fort Belvoir, Virginia.

9. Murrmann, R.P., Y. Nakano, T.J. Simpson, D.C. Leggett and D.M. Anderson (1971) Influence of soil on detection of buried explosives and tunnels by trace gas analysis. USA CRREL Research Report 288. AD 727667.

10. Murrmann, R.P., T.F. Jenkins and D.C. Leggett (1971) Composition and mass spectra of impurities in military grade TNT vapor. USA CRREL Special Report 158. AD 725474 .

11. Nicholson, B.J. and T.S. Shilliday (1967) Brief review on vapors from explosives and their detection. RACIC, Battelle Memorial Institute, Columbus, Ohio.

12. O'Reilly, W.F., T.F. Jenkins, R.P. Murrmann and R. Barriera (1973) Exploratory analysis of vapor impurities from TNT, RDX, and Comp-B. USA CRREL Special Report (in press). 


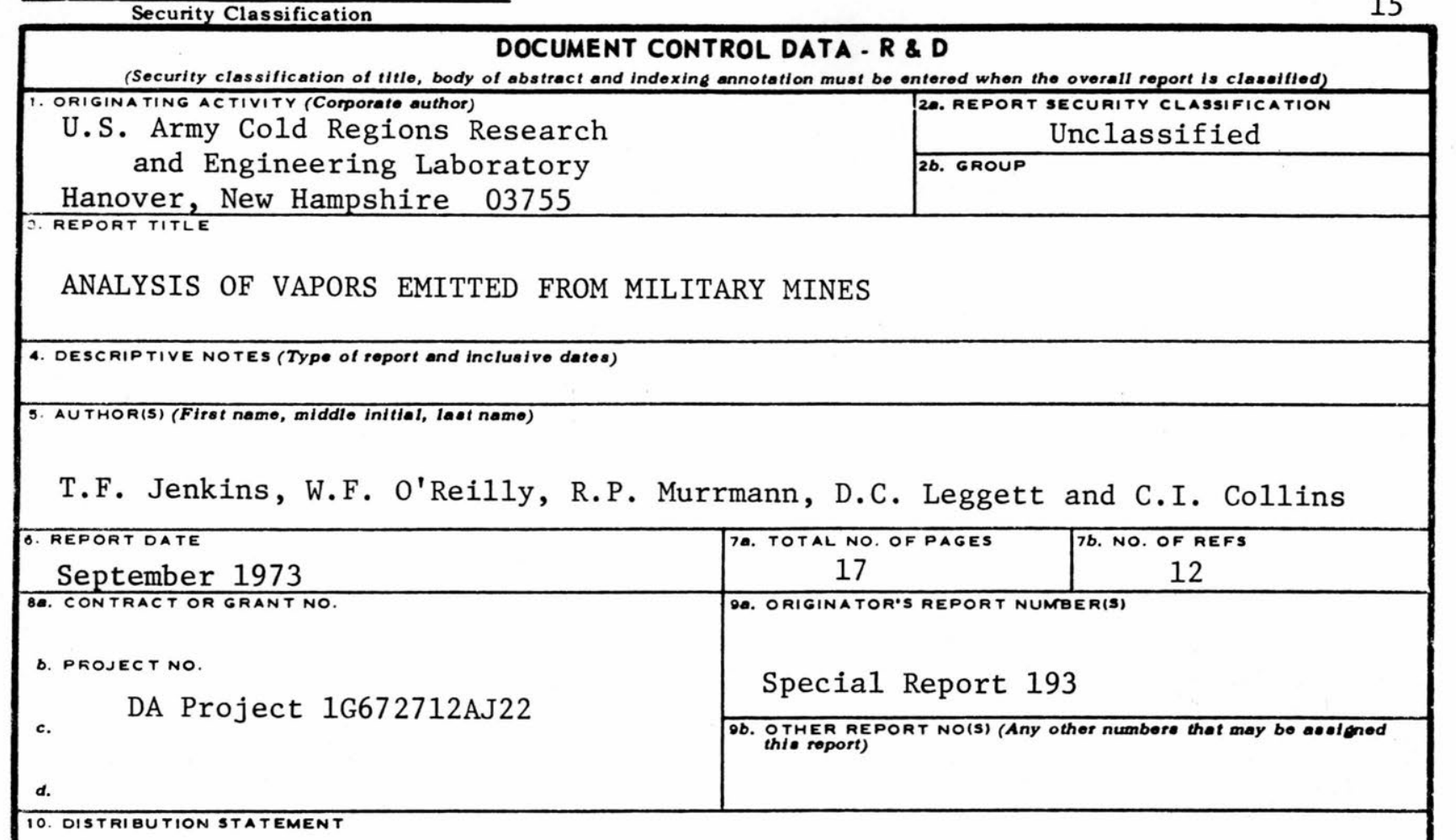

Approved for public release; distribution unlimited.

The vapor evolving from several types of intact military mines was analyzed using gas chromatography and gas chromatography/mass spectroscopy. Cyclohexanone was positively identified in the vapor from M15 (metallic) and M19 (nonmetallic) antitank mines. This compound originates from composition $B$, the explosive used in these mines. Acetone, toluene and an unknown organo-silicon compound were identified and are attributable to the nonmetallic mine casings. Although positive mass spectral identification is lacking, chromatographic data obtained using an electron capture detector indicated that 2, 4, 6 trinitrotoluene was detected in the vapor from the M16 (metallic) antipersonnel mines which are loaded with TNT.

14. Key Words

Explosives

Gas chromatography

Gas detectors

Gases
Land mine detection

Mine detectors

Mines (ordnance)

Trace gas detection 